\title{
Reasons of female children for elope with boyfriends in Anuradhapuradistrict of Sri Lanka
}

\author{
Senanayake SMHMK*
}

\begin{abstract}
Since Anuradhapura is a common district for elope of girl children with boyfriends, all medico legal examination forms of such cases examined by the author during last two years, were perused in order to find the reason for elope and about the awareness of legal age limit for the marriage. During the year 2015 and 2016, ninety-eight girls below the age of 18 who participated with elope had been examined by the author for medico legal purposes. They were within the age limit of 12 to 17 years. Forty two (42.8\%) girls were not aware about the legal age for marriage. Commonest reason for elope was the disapproval of love affair by parents in 54 cases $(56 \%)$. Other causes were; girls could not live at home in 17 cases $(17 \%)$, no special reason in 16 cases $(16 \%)$, issues related to sexual activities in 5 cases $(5 \%)$ and miscellaneous reasons in 6 cases $(6 \%)$. To minimize the elopement, psychosocial management of above five broad causes will be important. Research on reasons for elope from families and boyfriends will provide all groups of reasons for elopement in underage girls in the district.
\end{abstract}

Key words: Girl child, reasons, elope, parental disapproval, statutory rape

\section{Full paper \\ Introduction}

Even though sexual intercourse is illegal with females under the age of 16 years is named as statutory rape, some underage girls are arrested by police for eloping with boyfriends and engaged in sexual intercourse.

Elopement is a term that is used to describe the act of two lovers running away secretly for the purpose of getting married, often without parental consent. ${ }^{[1]}$ Some couples who elope do so in response to social pressures that are adverse to their union. ${ }^{[1]}$ Even though in most of the countries, elopement is typically met with very few legal penalties, it produces psychological trauma to family members

Consultant Judicial Medical officer, Teaching Hospital Anuradhapura, Sri Lanka

*Corresponding author:Senanayake SMHMK. Office of the JMO, Teaching Hospital, Anuradhapura, Sri Lanka. E-mail: senanayakekumara@yahoo.com. Tel: +94718195569

DOI: http://doi.org/10.4038/mljsl.v5i1.7347

https://orcid.org/0000-0002-0441-5970 and psychological, social and medical problems for the girl child. ${ }^{[2,3]}$

When reported to the police, all such elope cases before the age of 18 years are produced for medico legal examination because of involvement of offences such as statutory rape or abduction of the girl from parents. Studying the reasons for elope is important to understand the issue and to develop preventive plans.

\section{Method}

Since Anuradhapura a common district for elope of girl children, ${ }^{[4]}$ all the medico legal examinations of elope cases examined by the author during 2015 and 2016, were perused to find about the reason for elope and the awareness about the legal age limit for the marriage. Reason for elope and age limit for marriage are the routine questions asked during the medico legal examination. After obtaining permission from the head of the institution, medico legal examination forms belong to the author were perused. Data were extracted in to a data sheet consists of age of the examinee; knowledge about age of marriage and the 
reason for elope. Medico legal examination form number was not collected to protect the identity. Data extraction was done by the author and all forms were kept securely.

\section{Results}

During the years 2015 and 2016, ninety-eight girls below the age of 18 years who participated with Table 1: Age of distribution of examinees elope had been examined by the author for medico legal purposes. They were between 12 to 16 years of age. Age distribution of examinees is shown in Table 1.
Age of examinee

according to the year

12

13

14

15

16

17
Number of Examinees and percentage

( $\mathbf{N = 9 8 ) ~}$

$04(04)$

12 (12)

$02(02)$

$00(00)$
Of them, 42 (42\%) girls did not know about the legal age for marriage.

Various reasons for elope could be extracted from the histories of examinees. All the reasons could be broadly categorized in to five main groups. Group (A):Commonest reason was the disapproval of love affair by parents in 54 cases (56\%). Other causes were; Group (B):girls could not live at home in 17 cases (17\%), Group (C):no special reason in 16 cases (16\%), Group (D): miscellaneous reasons in 6 cases
$(6 \%)$ and $(\mathrm{E})$ :issues related to sexual activities in 5 cases (5\%). All 98 cases are divided in to above five broad groups and presented separately with the relevant portion of the history.

Group (A)Parents disliked the love affair: total number of cases is 54 out 98 and the section of the history indicated about disapproval of parents is shown in Table 2. 
Table 2: History section of examinees indicated about disapproval of parents

\section{Number of Examineesand percentage}

\section{Relevant part of the history}

$(\mathbf{N}=\mathbf{5 4})$

Parents advised to stop the love affair

One guardian had physically assaulted the examinee. (One mother, one aunt, one

$04(07)$

father and one stepfather)

Parents had planned to assault the boy friend

Parents of the boyfriend had advised to stop the love affair

Examinee thought that boyfriend is not suitable for the family and parents would not permit. (Three boys were poor and two boys had separated from first marriage)

Examinees were scared to go home. (Teacher had discovered the love affair, one couple had been seen by a teacher, two couple had been seen by cousins, three girls got late to go home than usual time after meeting with boyfriends)

Parents planed another marriage

$02(04)$

In group (B), the examinee had said she could not live at home anymore and wanted to go with the boyfriend and to start a separatelife. All has stated that parents do not love them and there were frequent arguments. Total number of cases is 17 out of 98 .
In group (C), the examinee could not express any reason for elope. Total number of cases is 16 out of 98.

Group (D) includes miscellaneous (special) reasons. Total number of cases is 6 out 98 and the history sections of examinees indicated about special (miscellaneous) reasons are shown in Table 3. 
Table 3: History section of examinee indicated about special reason

\section{Relevant part of the history}

\section{Number of Examinees}

Total $(\mathbf{N}=6)$

Parents approved the love affair and told they can marry at the age of 18 years. But they eloped.

One aunt and one uncle had advised the examinee to elope

1

Mother of boyfriend was ill. The examinee eloped to help her.

1

One examinee had no close relation to look after her

Examinee went to boyfriend's house to meet mother of boy. Then she wanted to stay there.

1

Group (E) includes the issues related to sexual activities. Total number of cases is 5 out 98 and the history sections of examinees indicated about sexual activities are shown in Table 4.

Table 4: History section of examinee indicated about sexual activities

\section{Relevant part of the history}

\section{Number of examinees}

\section{Total $(\mathbf{N}=5)$}

Examinee got pregnant by boyfriend

Examinee had engaged in sexual intercourse with boyfriend

Stepfather had tried to sexually harass the examinee
1

2

2

\section{Discussion}

Commonest cause for elope among underage female lovers in this study was the disapproval of the love affair by parents. According to the histories $56 \%$ of examinees expressed parental disapproval as scalding or assaulting by the parents or guardians and warning to stop the love affair. Parents of boyfriend had told the boy to stop the affair in only two cases. This observation indicates that reason (ex- disapproval) is mainly in the family of the girl. The second common cause was that girl could not live at home due to frequent arguments and lack of loving care by parents. Psycho-social support for the girl and parents are necessary to prevent this type of elopements. ${ }^{[5]}$ Third common group failed to express any reason for elope. When boyfriend proposed for elope, girl had simply complied. Fourth group was the miscellaneous group includes various rare reasons. In two cases, relatives had instructed them for elope. Practically at present in Sri Lanka, when a young girl 
elopes and couple was arrested by police, the boy is indicted for abduct or statutory rape. Court of law allows them to marry at the age of 18 before the judgment is pronounced. Awareness of this practical scenario, some adults seem to advise underage girls to elope with boyfriend to make sure the future marriage during the court procedure. Last group was related to sexual activities. According to Sri Lankan culture three girls could not think about any other marriage owing to consensual sexual intercourse with boyfriends and pregnancy. In two cases, step fathers had tried to sexually harass girls after discovering the love affair. To protect the girls, boyfriends had decided for elopements.

This study analyzed reasons expressed by girl child. Only 2 out 98 cases showed reasons related to boyfriends. In those cases, parents of boyfriends had told to stop the love affair. Group (C) which did not have any reason may be related to reasons belong to the boyfriend. This group shows that without any special reason some girls had agreed for elope to start a marriage life before the age of 16 years. Researches on boyfriends who participated with elope also important to identify all types of reasons for the elopement.

Even though law identifies the age of consent for sexual intercourse (16 years) and age for marriage $n($ 18 years), some girls want to engage in sexual activities and marriage life before the age of 16 years. This may be due to failure to educate the young children about sex and marriage life and failure to address the psychological and social needs of children by parents, teachers or social institutions. ${ }^{[6]}$

Eighty-two cases showed a reason which prevented girl living at home with parents till the age of 18 years. These cases could have been managed with psychological support and elopement could be prevented. In five cases, parent had assaulted the girl after discovering the love affair. In two cases, girl's parents had planned to assault the boyfriends. These 7 cases showed that physical child abuse is still happening in the society in relation to love affairs of teenagers. Eighty-two cases with a reason for elope showed those elopes were the result of impulsive reactions rather than planned activities. In some countries, legal age limit for marriage is 16 and lower as 14 with permission from the court of law. ${ }^{[7]}$ Sri Lankan legal systemdoes not permit marriage below 18 years even with parental permission or with the permission of court for the underage couples who participated elopement.

Researches on cause of elope in underage lovers are not found in literature. But lot of researches are available under the topic of "elope" because it includes wider range of elopements such as elope from hospitals, children homes, elderly homes and elope of autism children, dementic adults, psychiatry patients. Eloping of underage lovers is an area which needs more researches.

Because of the involvements of criminal law with elopement of young lowers, police arrest them on complains of parents. Forensic practitioners are routinely involved with these cases. If detail clinical history is taken, the real cause for elope such as previous criminal sexual offences by others are sometimes discovered. This small research also highlights the relevance of proper medicolegal management which includes the addressing of present incident, discovering of any underlying criminal cause, medical and psychosocial management of the victim and counseling of parents. Preventive measures according to the various causes should be taken by the society through awareness programs and counseling centers for children and parents.

\section{Conclusions}

When parents disapprove the love affair, when girl feels uncomfortable at home, when girl sexually harassed by guardians, when girl engage in consensual sexual intercourse with boyfriend or without any reason, some girls had participated with elopement. Researches on reasons related to boyfriends are necessary to understand all types of causes related to elopement.

\section{References}

1. Solernou DJ. Elopement. The Wiley Blackwell Encyclopedia of Family Studies. USA: University of Florida; 2016. [ cited 1.7.2017] 

$\begin{array}{lcc}\text { Available } & \text { from: } & \text { DOI: } \\ 10.1002 / 9781119085621 . \text { wbefs279 } & \end{array}$

2. Khanam K, Laksar BI. Causes and Consequences of Child Marriage - A Study of MilannagarShantipurVillage in Goalpara District. International Journal of Interdisciplinary Research in Science Society and Culture. 2015; 1(2) 100

3. Rathnayake R. Minimum age for marriage in Sri Lanka and girl child: bridging the gap in marriageable age. Annual academic Sessions 2012 of Open University of Sri Lanka; Colombo. 28th November 2012.

4. Colombage SM, Dasanayake PB, Waidyarathna DL. A study on child abuse in Anuradapura, Colombo South and Rathnapura. Colombo: Atlas Hall Ltd; 2005
5. Rubin KH, Dwyer KM, Booth-LaForce C, Kim AH, Burgess KB, Rose-Krasnor L. Attachment, Friendship, and Psychosocial Functioning in Early Adolescence. Journal of early Adolescence. 2004;24(4):326-56

6. Thalagala NI, Lokubalasooriya A, Danasuriya MN, Godakandage SP. National Youth Survey2012-13: Health profile and risk behaviors of the Sinhalese, Buddhist Unmarried Youth Stratum. Journal of the College of Community Physicians of Sri Lanka.2014:19(2)2-9

7. Spain raises marrying age from 14 to 16 . BBC News. 23 July 2015. Available at http://www.bbc.com/news/world-europe33636920 